\title{
A $\beta$-synuclein mutation linked to dementia produces neurodegeneration when expressed in mouse brain
}

\author{
Masayo Fujita', Shuei Sugama', Kazunari Sekiyama', Akio Sekigawa', Tohru Tsukui², Masaaki Nakai', \\ Masaaki Waragai', Takato Takenouchi',3, Yoshiki Takamatsu', Jianshe Wei', Edward Rockenstein ${ }^{4}$, \\ Albert R. LaSpada 5,6,7,8,9, Eliezer Masliah4, Satoshi Inoue ${ }^{2,10}$ \& Makoto Hashimoto ${ }^{1}$
}

The discovery of $\alpha$-synuclein ( $\alpha S$ ) mutations has made a major contribution to the understanding of the pathogenesis of $\alpha$-synucleinopathies such as Parkinson's disease and dementia with Lewy bodies (DLB). In contrast, less attention has been paid to $\beta$-synuclein ( $\beta S$ ) mutations. In this paper, we show that transgenic (tg) mice expressing DLB-linked P123H $\beta S$ develop progressive neurodegeneration, as characterized by axonal swelling, astrogliosis and behavioural abnormalities, with memory disorder being more prominent than motor deficits. Furthermore, cross-breeding of $\mathrm{P} 123 \mathrm{H} \beta \mathrm{S}$ tg mice with $\alpha \mathrm{S}$ tg mice, but not with $\alpha \mathrm{S}$ knockout mice, greatly enhanced neurodegeneration phenotypes. These results suggest that $\mathrm{P} 123 \mathrm{H} \beta \mathrm{S}$ is pathogenic and cooperates with pathogenic $\alpha S$ to stimulate neurodegeneration in mouse brain, indicating a causative role of P123H $\beta$ S in familial DLB. Given the neuritic pathology of $\beta S$ in sporadic $\alpha$-synucleinopathies, it appears that alteration of $\beta S$ can contribute to the pathogenesis of a broad range of $\alpha$-synucleinopathies.

\footnotetext{
1 Division of Chemistry and Metabolism, Tokyo Metropolitan Institute for Neuroscience, Tokyo 183-8526, Japan. ${ }^{2}$ Division of Gene Regulation and Signal Transduction, Research Center for Genomic Medicine, Saitama Medical University, Saitama 350-1241, Japan. ${ }^{3}$ Transgenic Animal Research Center, National Institute of Agrobiological Sciences, Tsukuba, Ibaraki 305-8634, Japan. ${ }^{4}$ Department of Neurosciences, University of California-San Diego, La Jolla, California 92093-0624, USA. ${ }^{5}$ Division of Genetics, Department of Pediatrics, University of California-San Diego, La Jolla, California 92093-0624, USA. ${ }^{6}$ Department of Cellular and Molecular Medicine, University of California-San Diego, La Jolla, California 92093-0624, USA. ${ }^{7}$ Division of Biological Sciences, University of California-San Diego, La Jolla, California 92093-0624, USA. ${ }^{8}$ Institute for Genomic Medicine, University of California-San Diego, La Jolla, California 92093-0624, USA. ${ }^{9}$ Rady Children's Hospital, San Diego, California 92193, USA. ${ }^{10}$ Department of Anti-Aging Medicine, Graduate School of Medicine, The University of Tokyo, Tokyo 113-8655, Japan. Correspondence and requests for materials should be addressed to M.H. (email: hashimoto-mk@igakuken.or.jp).
} 
$\beta$ -Synuclein $(\beta S)$ is an abundant pre-synaptic phosphoprotein that is found in the brain and is homologous to $\alpha$-synuclein $(\alpha S)^{1,2}$. Both proteins have been characterized on the basis of their native unfolded structures, but $\beta S$ is distinct from $\alpha S$ in that $\beta S$ lacks the majority of the hydrophobic non-amyloid- $\beta$ component of the Alzheimer's disease amyloid region ${ }^{3,4}$. Because of the presence of this highly amyloidogenic non-amyloid- $\beta$ component, $\alpha S$ is prone to self-aggregate and form toxic protofibrils, whereas $\beta S$ is less prone to form insoluble aggregates ${ }^{5-7}$. Several lines of evidence suggest that $\beta S$ may have a protective role against $\alpha$-synucleinopathies. In support of this notion, overexpression of $\beta S$ in $\alpha S$ transgenic ( $\operatorname{tg}$ ) mice by either crossing with $\beta$ S tg mice or using virus-mediated transfer results in amelioration of neuropathology (such as formation of Lewy body-like inclusions) and motor function deficits ${ }^{7-9}$. Mechanistically, $\beta S$ may directly inhibit aggregation and protofibrillar formation of $\alpha \mathrm{S}$, as demonstrated under cell-free conditions ${ }^{7,10,11}$. An alternative mechanism may include a role of lipids, as it has been shown that oligomerization of $\alpha \mathrm{S}$ is dramatically enhanced by increasing the cellular levels of polyunsaturated fatty acids ${ }^{12}$, which was inhibited by polyunsaturated fatty acid-associated $\beta S$ in mesencephalic cells ${ }^{13}$.

In this context, it is of note that two missense mutations of $\beta S, \mathrm{P} 123 \mathrm{H}$ and V70M, have been linked to familial and sporadic dementia with Lewy bodies (DLBs), respectively ${ }^{14}$. It is possible that the DLB-linked $\beta S$ mutants might have lost protective functions against the neurotoxicity caused by $\alpha \mathrm{S}^{14}$. However, given the autosomal dominant trait of patients with the $\mathrm{P} 123 \mathrm{H}$ mutation ${ }^{14}$, toxic gains of function of $\beta S$ through gene mutation might contribute to the pathogenesis of familial DLB. In support of the latter possibility, our recent study showed that both $\mathrm{P} 123 \mathrm{H}$ - and V70M-recombinant $\beta S$ proteins were prone to aggregate in vitro and that expression of these mutant $\beta S$ proteins in neuroblastoma cells resulted in lysosomal pathology associated with protein aggregation ${ }^{15,16}$.

Although DLB is the second most common cause of dementia after Alzheimer's disease ${ }^{17}$, the pathogenic mechanism of DLB is poorly understood. Elucidation of the mechanism through which DLB-linked $\beta S$ mutations cause neurodegeneration in vivo may provide us with some insights into this critical issue. Accordingly, the main objective of this study was to investigate the neuropathology of DLB-linked P123H $\beta S$ through analysis of $t g$ mice. The results show that tg mice expressing $\mathrm{P} 123 \mathrm{H} \beta \mathrm{S}$ were characterized by neuritic pathology, associated with astrogliosis and behavioural abnormalities. Furthermore, the neuropathology of $\mathrm{P} 123 \mathrm{H} \beta \mathrm{S}$ tg mice was not significantly affected by cross-breeding with $\alpha \mathrm{S}$ knockout (KO) mice. On the other hand, cross-breeding of $\mathrm{P} 123 \mathrm{H} \beta \mathrm{S}$ tg mice with $\alpha \mathrm{S}$ tg mice resulted in enhanced phenotypes, including neuronal cell loss and dopaminergic dysfunction. These results strongly suggest that $\mathrm{P} 123 \mathrm{H} \beta \mathrm{S}$ is by itself pathogenic and cooperates with pathogenic $\alpha \mathrm{S}$ to stimulate neurodegeneration.

\section{Results}

Neuropathological characterization of $\mathrm{P} 123 \mathrm{H} \beta \mathrm{S} \operatorname{tg}$ mice. We generated tg mice overexpressing $\mathrm{P} 123 \mathrm{H} \beta \mathrm{S}$ under the control of the Thy-1 promoter (Fig. 1a,b). In all lines of tg mice with $\mathrm{P} 123 \mathrm{H}$ $\beta S$ mRNA expression in the brain (Fig. 1c), P123H $\beta S$ expression was also detected at the protein level (Fig. 1d). Mice from line C had the highest levels of transgene expression, followed by the two intermediate expressers, lines B and $\mathrm{G}$, and the three low expressers, lines A, D and E. Lines C and B were analysed in the majority of experiments.

Histopathological analyses revealed that $\mathrm{P} 123 \mathrm{H}$ BS mice are characterized by extensive neuritic pathology. For instance, $\mathrm{P} 123 \mathrm{H}$ $\beta S$ accumulated in various brain regions as early as 6 months of age, including in apical dendrites in the cortex and in axonal deposits in the hippocampus (Fig. 2a). Given the lack of $\beta$ S immunoreactivity for Lewy bodies formed in the autopsy brain with $\mathrm{P} 123 \mathrm{H} \beta S$ mutation ${ }^{14}$,
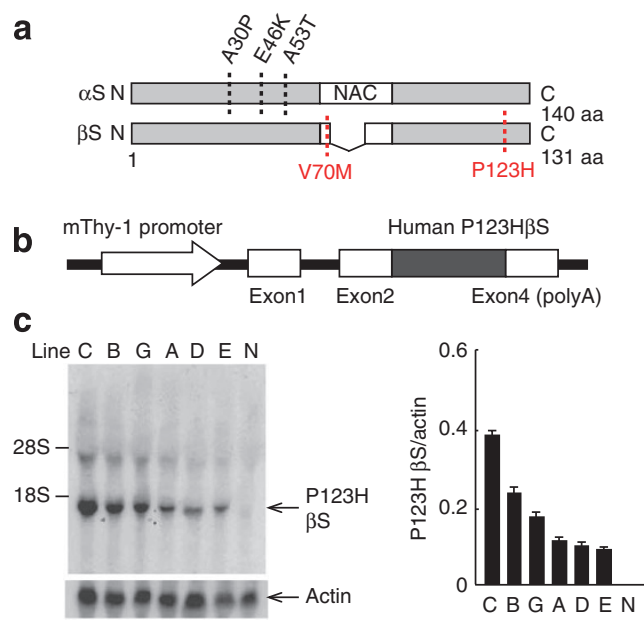

d
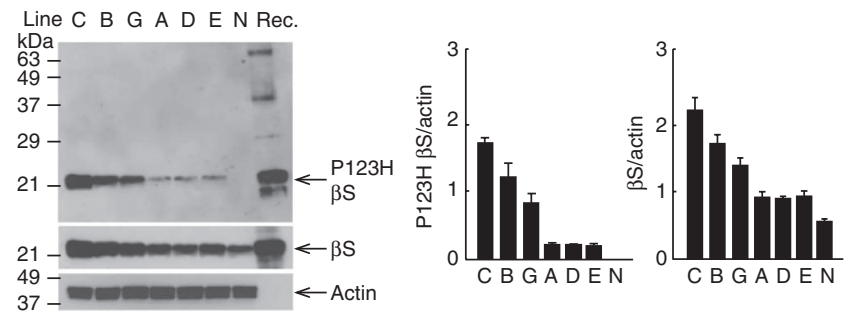

Figure 1 | Generation of P123H $\boldsymbol{\beta S}$ tg mice. (a) Scheme shows missense mutations of $\alpha S$ and $\beta S$ identified in $\alpha$-synucleinopathies. Two $\alpha S$ mutations, $\mathrm{A}_{30 \mathrm{P}^{45}}$ and $\mathrm{A} 53 \mathrm{~T}^{46}$, were discovered in $\mathrm{PD}$, and another $\alpha \mathrm{S}$ mutation, E46K ${ }^{47}$, was later found in DLB. As for $\beta S$, two mutations, V70M and $\mathrm{P} 123 \mathrm{H}$, have been reported in $\mathrm{DLB}^{14}$. (b) Diagrammatic representation of the Thy-1-P123H $\beta$ S construct. (c) Northern blot analysis of $\mathrm{P} 123 \mathrm{H} \beta \mathrm{S}$ mRNA. Total RNA (10 $\mu$ g) prepared from P123H $\beta$ S tg (lines C, B, G, A, D and $\mathrm{E}$ ) and non-tg (N) mice brains at 4 months was analysed by northern blotting using ${ }^{32} \mathrm{P}$-labelled P123H $\beta$ S cDNA (upper panel). The filters were reprobed with ${ }^{32} \mathrm{P}$-actin cDNA (lower panel). Representative blots and data quantified against actin bands are shown as the mean \pm s.e.m. $(n=3)$. Endogenous mouse $\beta S$ mRNA was hardly detected with human $\mathrm{P} 123 \mathrm{H} \beta \mathrm{S}$ cDNA probe under the current experimental conditions. (d) Immunoblot analysis of $\mathrm{P} 123 \mathrm{H} \beta \mathrm{S}$ protein. Total brain extracts $(10 \mu \mathrm{g})$ prepared from $\mathrm{P} 123 \mathrm{H} \beta \mathrm{S} \operatorname{tg}$ (lines C, B, G, A, D and E) and non-tg (N) mice at 4 months were analysed using anti- $\mathrm{P} 123 \mathrm{H} \beta \mathrm{S}$ antibody, which recognizes $\mathrm{P} 123 \mathrm{H} \beta \mathrm{S}$ but not mouse wt $\beta$ S (upper panel) (Supplementary Table S2). The blots were reprobed with anti- $\beta \mathrm{S}$ antibody, which recognizes both $\mathrm{P} 123 \mathrm{H} \beta \mathrm{S}$ and mouse wt $\beta S$ (middle panel) and anti-actin antibody (lower panel). Recombinant $\mathrm{P} 123 \mathrm{H} \beta \mathrm{S}$ (Rec.) ${ }^{15}$ was used as positive control. Representative blots and data quantified against actin bands are shown as the mean \pm s.e.m. $(n=3)$. NAC, non-amyloid- $\beta$ component.

it was not unexpected that Lewy body-like inclusions were not observed in $\mathrm{P} 123 \mathrm{H}$ BS tg mice. However, one prominent feature of these mice was the formation of $\mathrm{P} 123 \mathrm{H} \beta \mathrm{S}$-immunoreactive axonal swellings in the striatum and globus pallidus (Fig. 2b). The number of swellings was well correlated with the expression level of $\mathrm{P} 123 \mathrm{H} \beta \mathrm{S}$ and was observed in an age-dependent manner (Fig. 2b). Consistent with an abnormal accumulation of $\mathrm{P} 123 \mathrm{H} \beta \mathrm{S}$, the same regions were accompanied by massive gliosis, as revealed by an increased level of glial fibrillary acidic protein (GFAP)positive astroglia (Supplementary Fig. S1a-c). In contrast to $\mathrm{P} 123 \mathrm{H}$ $\beta S$ mice, neither abnormal immunostaining of $\mathrm{P} 123 \mathrm{H} \beta \mathrm{S}$ nor gliosis was observed in both non-tg littermates and mice overexpressing wild-type (wt) $\beta S$ (Fig. 2a-c, Supplementary Fig. S1a-c).

Electron microscopy (EM) revealed that the swellings were 'globules': small spheroids that are frequently associated with axonal 
dystrophy (Fig. 2d) ${ }^{18,19}$. The globules were composed of small vesicles and frequently contained membranous elements such as multivesicular bodies and multilayered membranes. Furthermore, the globules were surrounded by a single membrane with association of no myelin sheaths and no post-synaptic contacts, suggesting that these globules are not functional terminals. Moreover, LC3-positive dots were observed in the globules with an increased amount of LC3-II, a marker of autophagosomes ${ }^{20}$ (Supplementary Fig. S1d,e). Because cathepsins B and D activities, but not proteasome activities, were significantly decreased in $\mathrm{P} 123 \mathrm{H} \beta \mathrm{S}$ tg mice compared with non-tg littermates (Supplementary Fig. S1f-i), it is probable that autophagosomes might accumulate in the globules because of decreased clearance by lysosomes.

Notably, double immunofluorescence study showed that the $\mathrm{P} 123 \mathrm{H} \beta \mathrm{S}$-positive globules were highly immunoreactive with anti- $\alpha \mathrm{S}(\sim 100 \%)$ and to a lesser extent with anti-ubiquitin $(\sim 70 \%)$ (Fig. 2e), indicating that endogenous $\alpha \mathrm{S}$ and ubiquitinated proteins accumulated because of compromised degradation at the lysosome. A further study revealed that $\mathrm{P} 123 \mathrm{H} \beta \mathrm{S}$-positive globules were also immunostained with both anti- $\gamma$-aminobutyric acid (anti-GABA) and antiglutamic acid decarboxylase antibodies ( $100 \%$; Fig. $2 \mathrm{e})$. Although few GABAergic neurotransmitters in the basal ganglia, such as dynorphin, enkephalin and substance $\mathrm{P}$, were detected in the globules, a weak immunoreactivity of calbindin was consistently detected (Supplementary Fig. S2), suggesting that the globules were formed in projection-type GABAergic neurons. Because synaptic markers such as synaptophysin and synapsin I and axonal markers including neurofilaments were not detectable (Supplementary Fig. S2), the results suggest again that these GABAergic neuronal terminals are no longer functional. Degeneration of these neurons by $\mathrm{P} 123 \mathrm{H} \beta \mathrm{S}$ may be important, as there is ample evidence showing that GABAergic neurons in the striatum, which functions as the second component of the Parkinsonian circuit, are significantly altered in Parkinson's disease (PD) brains ${ }^{21}$.

Consistent with the histopathological changes, biochemical analyses showed that expression of $\mathrm{P} 123 \mathrm{H} \beta \mathrm{S}$ was increased in an age-dependent manner, particularly in formic acid (FA) fractions, indicating a gradual accumulation of insoluble $\mathrm{P} 123 \mathrm{H} \beta \mathrm{S}$ (Supplementary Fig. S3a). Compared with P123H $\beta S$ tg mice, no accumulation of wt $\beta S$ was observed in FA fractions of wt $\beta S$ tg mice (Supplementary Fig. S3b). Furthermore, upregulation of heatshock proteins (HSPs), including HSP70 and HSP25, was already apparent at 6 months, whereas expression of synaptic markers, such as SNAP25 and VAMP2, were decreased at 18 months, suggesting that the protective capacity in $\mathrm{P} 123 \mathrm{H} \beta \mathrm{S}$ tg mice might be insufficient at this age (Supplementary Fig. S3c).

Finally, P123H $\beta S$ tg mice exhibited various types of abnormal behaviours. To determine the effects of $\mathrm{P} 123 \mathrm{H} \beta \mathrm{S}$ accumulation on spatial learning and memory, a water maze test was conducted (Fig. 3). In the training sessions, $\mathrm{P} 123 \mathrm{H} \beta \mathrm{S}$ mice showed significant learning deficits, whereas non-tg controls performed normally (Fig. 3a). Furthermore, P123H $\beta S$ mice showed significantly less preference for the target quadrant than non-tg littermates, suggesting impaired retention of spatial memory (Fig. 3b,c). During the same stage, a home cage test demonstrated that various spontaneous activities were decreased in $\mathrm{P} 123 \mathrm{H} \beta \mathrm{S}$ tg mice (line C) compared with non-tg littermates (Fig. 3d). In contrast, a rotarod treadmill test showed that motor deficits were not observed in the middle stage ( 6 months) but became apparent during the late stage (12-18 months) in P123H $\beta S$ tg mice (Fig. 3e).

Neuropathology of P123H $\beta S$ tg mice is not affected by deletion of $\alpha \mathrm{S}$. The analysis of $\mathrm{P} 123 \mathrm{H} \beta \mathrm{S}$ tg mice unambiguously shows that $\mathrm{P} 123 \mathrm{H} \beta \mathrm{S}$ is pathogenic in mouse brain. However, it is unclear whether endogenous murine $\alpha \mathrm{S}$ has any role in the neuropathology of $\mathrm{P} 123 \mathrm{H} \beta \mathrm{S}$ tg mice. This important question was addressed by a cross-breeding experiment of $\mathrm{P} 123 \mathrm{H} \beta \mathrm{S}$ tg with $\alpha \mathrm{S}$ KO mice (Supplementary Methods), in which various neurodegeneration phenotypes, including neuritic pathology (Supplementary Fig. S4a), formation of globular axonal swelling (Supplementary Fig. S4b), protein aggregation (Supplementary Fig. S4c) and astrogliosis (Supplementary Fig. S4d,e), were compared. The results showed that none of these neurodegenerative features were significantly different between $\mathrm{P} 123 \mathrm{H} \beta \mathrm{S}$ and $\mathrm{P} 123 \mathrm{H} \beta \mathrm{S} / \alpha \mathrm{S} \mathrm{KO}$ tg mice, indicating that endogenous $\alpha \mathrm{S}$ may not be necessarily required for the neuropathology of $\mathrm{P} 123 \mathrm{H} \beta \mathrm{S}$.

Enhanced neuropathology in P123H $\beta S / \alpha S$ double tg mice. Next, a further cross-breeding experiment of $\mathrm{P} 123 \mathrm{H} \beta \mathrm{S}$ tg with $\alpha \mathrm{S}$-overexpressing tg mice was conducted to assess the combined effects of $\mathrm{P} 123 \mathrm{H} \beta \mathrm{S}$ and pathogenic $\alpha \mathrm{S}$ on neurodegeneration (Supplementary Methods). The neuropathological characterization of Thy-1 promoterdriven $\alpha$ S-expressing tg mice was previously reported ${ }^{22}$, indicating that overexpressed $\alpha \mathrm{S}$ is pathogenic in mouse brain. As we expected, bigenic mice overexpressing $\mathrm{P} 123 \mathrm{H} \beta \mathrm{S}$ and $\alpha \mathrm{S}$ showed an enhanced neurodegenerative phenotype compared with each monogenic tg mouse. Besides lower body weight and high mortality (Supplementary Fig. S5a,b), bigenic mouse brains were characterized by increased protein aggregation, as demonstrated by the increased level of both $\alpha S$ and P123H $\beta S$ in FA fractions (Supplementary Fig. S5c). Furthermore, expression of synapse proteins, such as VAMP2, SNAP25 and PSD95, was decreased in bigenic mice compared with littermates (Supplementary Fig. S5d). Moreover, various pro-inflammatory factors, including interleukin $1 \beta$ (IL-1 $\beta$ ), IL-6, tumour necrosis factor- $\alpha$, induced nitrogen oxide synthase and monocyte chemotactic protein-1, were significantly upregulated in bigenic mice compared with littermates, suggesting that neuroinflammation was enhanced in bigenic mice (Supplementary Fig. S6a). Indeed, morphologically activated astrocytes and microglia were occasionally observed in bigenic mice but not in littermates (Supplementary Fig. S6b,c). Because IL-1 $\beta$ colocalized well with GFAP but not with CD11b, it was predicted that astrocytes may have a dominant role in inflammation in this stage (Supplementary Fig. S6d,e).

During the terminal stage ( $\sim 9$ months) of bigenic mice, numerous phospho-c-Jun- and c-Fos-positive nuclei were observed in the hippocampus and cortex, suggesting that neurons in bigenic mice are subjected to chronic stress (Fig. 4a,b). Concordant with these findings, Fluoro Jade C (FJC)-positive degenerating neurons were occasionally observed in bigenic mice and to a lesser extent in $\alpha S$ tg mice (Fig. 4c). Given the immunoreactivity of $\alpha S$ in FJCpositive neurons, accumulated $\alpha \mathrm{S}$ might directly and continuously injure neurons, leading to stimulation of neurodegeneration (Fig. 4c). Such a chronic process of neurodegeneration may eventually lead to neuronal loss, as the numbers of NeuN-immunopositive neurons in the hippocampus of bigenic mice were significantly lower than those of monogenic tg mice and of nontg littermates (Fig. 4d). Nevertheless, terminal deoxynucleotidyl transferase dUTP nick end labelling (TUNEL)-positive neurons were not convincingly detected (Fig. 4e), suggesting that nonapoptotic neuronal cell death may at least partly contribute to neuronal loss in bigenic mice. Similar TUNEL-negative neuronal death has been documented in various types of neurodegeneration, including degeneration of dopaminergic neurons induced by 6-hydroxydopamine, axotomy and 1-methyl-4-phenyl-1,2,3,6tetrahydropyridine (MPTP) in adult mice ${ }^{23,24}$. Finally, EM studies consistently demonstrated the presence of degenerating dark neurons in the hippocampus and cortex of bigenic brains, but not in littermates (Fig. 4f). Although the mechanism is unknown, dark neurons are induced under a variety of pathological conditions, including ischaemia, epilepsy and head injury ${ }^{25}$. Furthermore, dark neurons have been described in a mouse model and in the 

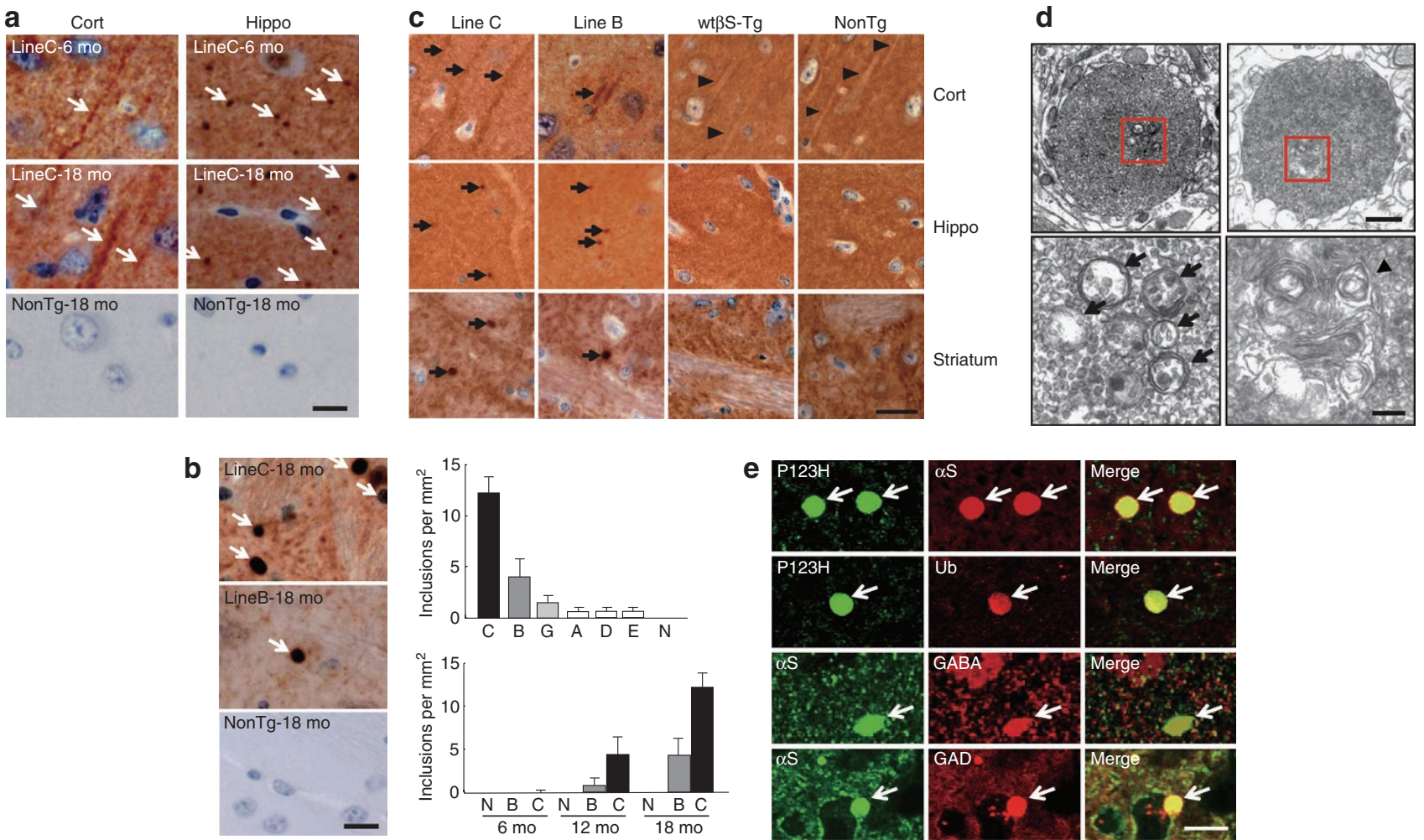

Figure 2 | P123H $\beta$ S tg mice are characterized by a neuritic pathology. (a, b) Immunohistochemistry of P123H $\beta S$ using anti-P123H $\beta S$ antibody. In $\mathbf{a}, \mathrm{P} 123 \mathrm{H} \beta \mathrm{S}$ accumulated in apical dendrites in the cortex (cort, left panels) and in axonal dots in the hippocampus (hippo, right panels) (6 and 18 months (mo)) of $\mathrm{P} 123 \mathrm{H} \beta \mathrm{S}$ tg mice (line $\mathrm{C}$, arrows), but not in the same regions of non-tg littermates (NonTg). Scale bar $=10 \mu \mathrm{m}$. (b) Globules were observed in the striatum and globus pallidus of 18-month-old P123H $\beta$ S tg mice (lines B and C, arrows), but not in non-tg littermates. Scale bar $=10 \mu \mathrm{m}$. For quantification, five images were analysed for each mouse and the results were used to calculate the average number of globules per mm². Upper panel: multiple lines $C, B, G, A, D$ and $E$, and non-tg $(N)$ at 18 months; lower panel: lines $B, C$ and $N$ at 6, 12 and 18 months. Data are shown as the mean \pm s.e.m. $(n=7)$. (c) Immunohistochemistry of total $\beta S$ using anti- $\beta S$ antibody. $\beta S$ accumulated in apical dendrites in the cortex (cort), and in axonal dots in the hippocampus (hippo) of 18-month-old P123H $\beta$ S mice (lines C and B, arrows), but not in wt $\beta$ S tg mice (wt $\beta S$ - Tg) and non-tg littermates (NonTg). Arrowheads indicate negative staining of $\beta \mathrm{S}$ in apical dendrites. Similarly, formation of globules in the striatum was observed in 18-month-old P123H $\beta S$ mice (arrows), but not in age-matched wt $\beta S \mathrm{tg}$ mice and non-tg mice. Scale bar $=20 \mu \mathrm{m}$. (d) Photomicrographs of two representative globules in 18-month-old tg mice (line C). The lower two panels are insets from the two higher panels. Globules were composed of small vesicles and contained multivesicular bodies (arrows) and autophagosome-like multiple-layered membranous structures (arrowheads). Scale bar $=1 \mu \mathrm{m}$ (upper panel) and $200 \mathrm{~nm}$ (lower panel). (e) Anti-P123H $\beta$ S-immunopositive globules formed in the basal ganglia of P123H $\beta$ S tg mice (line C, 18 months) were double stained with either anti- $\alpha S$ or anti-ubiquitin (Ub) (upper six panels). Alternatively, anti- $\alpha S$-immunopositive globules were stained with anti- $\alpha S$ and either anti-GABA or anti-glutamic acid decarboxylase (anti-GAD) (lower six panels). The slides were observed by laser scanning confocal microscopy. Arrows point to globules. Scale bar $=10 \mu \mathrm{m}$.

brain of a patient affected by Huntington's disease ${ }^{26}$, as well as in an $\alpha S$-conditioned mouse model of $\mathrm{PD}^{27}$ and in a MPTP-treated mouse model of $\mathrm{PD}^{28}$. Considering that conventional $\alpha \mathrm{S}$ tg mice rarely exhibit neuronal death, our bigenic mice may be a powerful tool with which to investigate the mechanism of neuronal death in neurodegenerative diseases.

Finally, several findings suggested that dopaminergic dysfunction might be involved in motor dysfunctions of bigenic mice during the middle stage (4-7 months). First, strong clasping was observed in bigenic mice but not in other littermates (Fig. 5a). Clasping behaviour has never been observed in C57BL/6 mice during this stage in routine experiments. Furthermore, clasping has been described in various models of nigrostriatal anomalies ${ }^{29,30}$. Second, locomotor performance was significantly impaired in bigenic mice compared with $\alpha \mathrm{S}$ tg mice and other littermates (Fig. 5b). Third, the levels of tyrosine hydroxylase ( $\mathrm{TH})$ and other dopaminergic markers, including L-dopa decarboxylase and dopamine transporter, were significantly decreased in the basal ganglia (Fig. 5c,d), although it was unclear whether the motor deficits were entirely attributable to the modest decrease $(\sim 40 \%)$ in the dopamine concentration (Fig. 5e). In addition, the number of globules in basal ganglia was significantly higher in bigenic mice compared with $\mathrm{P} 123 \mathrm{H}$ BS mice (Supplementary Fig. S7). One may speculate that globule formation of GABAergic projection neurons was stimulated by the compensatory mechanism in response to decreased dopaminergic inputs in bigenic mice. Taken together, these results suggest that motor deficits of bigenic mice are attributed to axonal degeneration of nigrostriatal dopaminergic neurons.

\section{Discussion}

This study demonstrates that $\mathrm{P} 123 \mathrm{H} \beta \mathrm{S}$ is itself pathogenic, and endogenous murine $\alpha \mathrm{S}$ is dispensable to the neuropathology of P123H $\beta S$ tg mice. On the other hand, bigenic mice overexpressing $\mathrm{P} 123 \mathrm{H} \beta \mathrm{S}$ and human $\alpha \mathrm{S}$ exhibited enhanced neuropathology. These results strongly suggest that $\mathrm{P} 123 \mathrm{H} \beta \mathrm{S}$ may cooperate with the pathogenic (overexpressed) state of $\alpha S$, but not with normal $\alpha S$, to stimulate neurodegeneration. In this context, it is possible that aggregation of $\alpha \mathrm{S}$ in the $\mathrm{P} 123 \mathrm{H} \beta \mathrm{S}$ brains of patients might be stimulated not only by $\mathrm{P} 123 \mathrm{H} \beta \mathrm{S}$ but also by other factors, such as ageing, genetic factors and environmental risks. Such a notion is in line with the incomplete dominant inheritance in a familial DLB associated with $\mathrm{P} 123 \mathrm{H} \beta \mathrm{S}$ mutation and could partly explain Lewy 
a

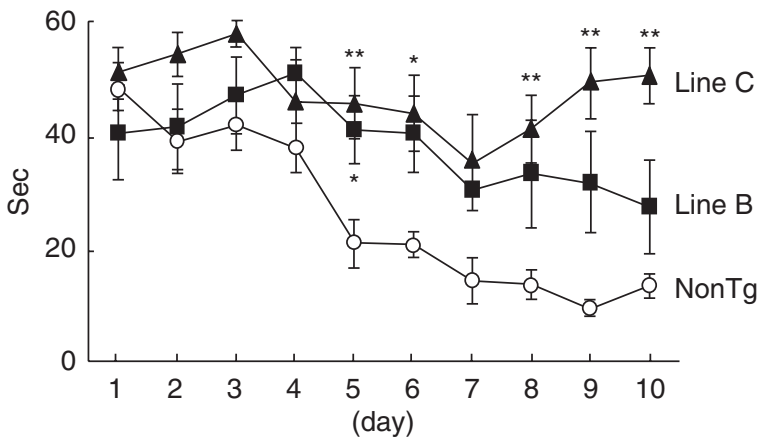

b

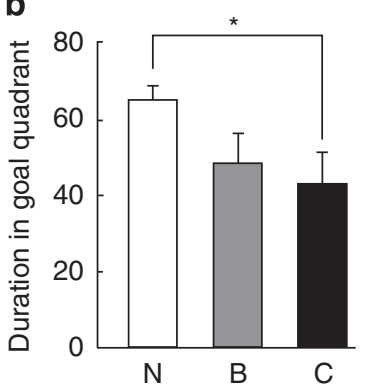

c

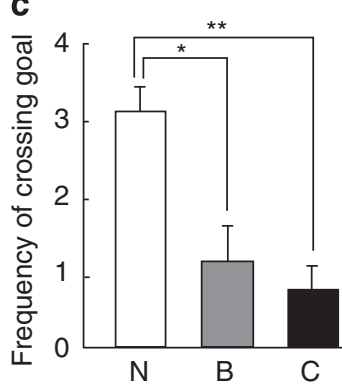

d

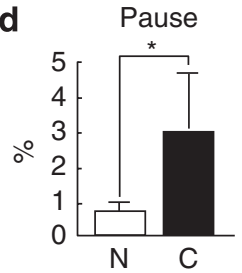

Groom

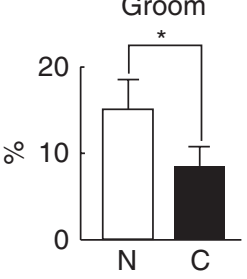

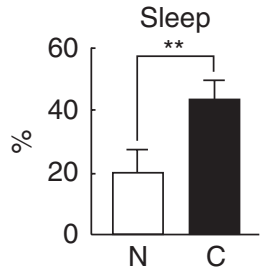

Sniff

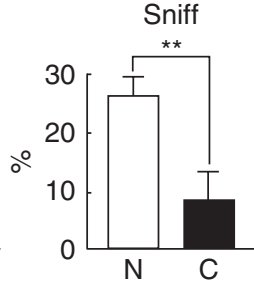

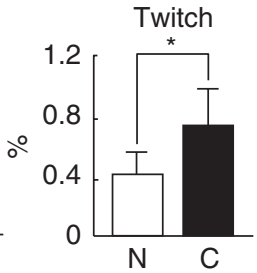

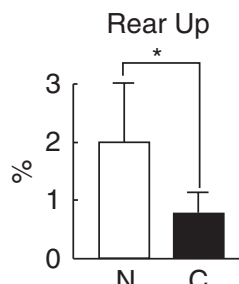

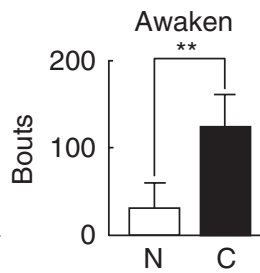

Hang Vertically

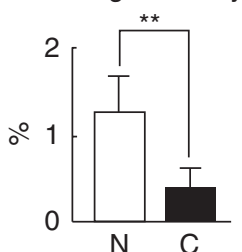

e

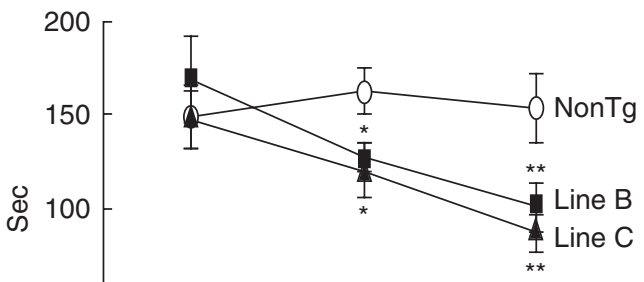

Figure 3 | Behavioural abnormalities of P123H $\mathbf{\beta S}$ tg mice. (a-c) The Morris water maze test. Compared with non-tg littermates (NonTg), P123H $\beta$ S $\operatorname{tg}$ mice (lines $B$ and $C$ ) at 6 months (mo) did not show an improvement in performance during the training session (a). After removing the platform, a probe test was performed on the last day of the training session $(\mathbf{b}, \mathbf{c}) . \mathrm{P} 123 \mathrm{H} \beta \mathrm{S}$ tg mice spent less time searching in the target quadrant than did non- $\mathrm{Tg}$ $(\mathrm{N})$ mice (b). Similarly, P123H $\beta \mathrm{S}$ tg mice had less frequency of crossing the goal (c). Data are shown as the mean \pm s.e.m. $(n=7-11)$. ${ }^{\star} P<0.05$, ${ }^{\star \star} P<0.01$ versus non-tg mice. (d) Home cage test showing decreased spontaneous activities in P123H BS tg mice (line C) compared with non-tg littermates at 6 months. Time spent in various types of behaviours, including 'Pause' 'Sleep' 'Twitch', 'Groom', 'Sniff', 'Rear up' and 'Hang Vertically', was measured using a video tracking system. 'Awaken' is the end of sleep during this period. Data are shown as mean \pm s.e.m. $(n=7)$. ${ }^{\star} P<0.05$, ${ }^{\star \star} P<0.01$ versus non-tg mice. (e) The rotarod treadmill test showing impaired motor performance in $\mathrm{P} 123 \mathrm{H} \beta \mathrm{S}$ tg mice compared with non-tg littermates (NonTg) at different ages. Data are shown as mean \pm s.e.m. $(n=8-10) .{ }^{\star} P<0.05,{ }^{\star \star} P<0.01$ versus non-tg mice.

body pathology in the postmortem brain of the patient ${ }^{14}$. It is also intriguing that the present results are in contrast to previous studies showing that neuropathological features of $\alpha \mathrm{S} \operatorname{tg}$ mice were ameliorated in bigenic mice overexpressing $\alpha \mathrm{S}$ and wt $\beta \mathrm{S}^{7,8}$. Collectively, one possible interpretation is that the neuroprotective $\beta$ S might be converted to a neurotoxic molecule by the $\mathrm{P} 123 \mathrm{H}$ mutation, leading to stimulation of $\alpha \mathrm{S}$ pathology.

The precise mechanism of neurotoxic conversion of $\beta S$ by the $\mathrm{P} 123 \mathrm{H}$ mutation is currently unknown. In this regard, it is of note that the C-terminal region of $\beta S$ is composed of a polyproline II helix, unfolding of which may have an important role in proteinprotein interactions $^{31}$. Thus, the $\mathrm{P} 123 \mathrm{H}$ substitution may affect the polyproline II helix structure, resulting in a conformational change and misfolding of $\beta S$ that leads to stimulation of $\alpha S$ oligomerization. Because the C-terminal region of $\beta S$ is subjected to post-translational modification through phosphorylation ${ }^{1}$ and glycosylation ${ }^{32}$, it is also possible that aberrant regulation of the $\mathrm{C}$-terminal region by various stimuli may contribute to the involvement of $\beta S$ in sporadic cases of $\alpha$-synucleinopathies. Indeed, the neuritic pathology of $\mathrm{P} 123 \mathrm{H} \beta \mathrm{S}$ mice is reminiscent of previous reports showing that $\beta S$ and $\gamma$-synuclein $(\gamma S)$, the third member of the synuclein family of peptides, are associated with neuritic pathology, such as in dystrophic neurites and spheroid structures, in the brains of sporadic cases of PD, DLB and neurodegeneration with brain iron accumulation, type $1^{33,34}$. Our findings and a recent report showing that overexpression of $\gamma S$ results in neurodegeneration in mouse brain $^{35}$ indicate the need for future studies to determine whether altered $\beta S$ and possibly $\gamma S$ may cooperate with $\alpha S$ in the pathogenesis of a broad range of $\alpha$-synucleinopathies.

\section{Methods}

Summary of the generation and analysis of tg mice. All animal procedures were approved and conducted in accordance with Animal Ethics Review Committee regulations of the Tokyo Metropolitan Institute for Neuroscience.

For generation of tg mice expressing P123H $\beta S$, human P123H $\beta S$ cDNA was released from a PCEP4-P123H $\beta S$ vector ${ }^{15}$ and inserted into the XhoI site of the mouse Thy- 1 expression cassette (kindly supplied by Dr H van der Putten, CibaGeigy). The Thy-1-P123H $\beta$ S plasmids were microinjected into fertilized eggs of C57BL/6 mouse and multiple lines of Thy-1-P123H $\beta$ S tg mice were generated.

Thy $1-\alpha S \operatorname{tg}$ mice and Thy1-wt $\beta S$ tg mice were both primarily established as DBA2 $\times$ C57BL/6 hybrids ${ }^{7,22}$. These mice were maintained by successive (more than seven generations) backcrossing into the C57BL/6 strain. Heterozygote Thy1-P123H BS tg mice (line C: the highest expresser) were further crossed with heterozygote Thy $1-\alpha S$ tg mice to generate bigenic mice overexpressing human $\mathrm{P} 123 \mathrm{H} \beta S$ and human $\alpha \mathrm{S}$, and littermates including P123H $\beta S$ tg mice, $\alpha \mathrm{S}$ tg mice and non-tg mice. Genomic DNA was extracted from tail biopsies, and genotyping of P123H $\beta S$ and human $\alpha S$ was performed by PCR using specific primers (Supplementary Table S1). The tg mice were evaluated by histological and biochemical analyses using various antibodies (Supplementary Methods, Supplementary Table S2), in addition to several behavioural tests.

Tissue processing of tg mice brain. Mice brains were removed under deep anaesthesia and divided sagittally. One hemibrain was snap frozen in liquid nitrogen and stored at $-80^{\circ} \mathrm{C}$ for biochemical studies and RNA analysis. Hippocampus and cortex samples were collected from the region $1.8-2.8 \mathrm{~mm}$ posterior to the bregma, whereas striatum samples were obtained from the region $0-1 \mathrm{~mm}$ anterior to the bregma. The other hemibrain was fixed in Bouin's solution and embedded in 
a

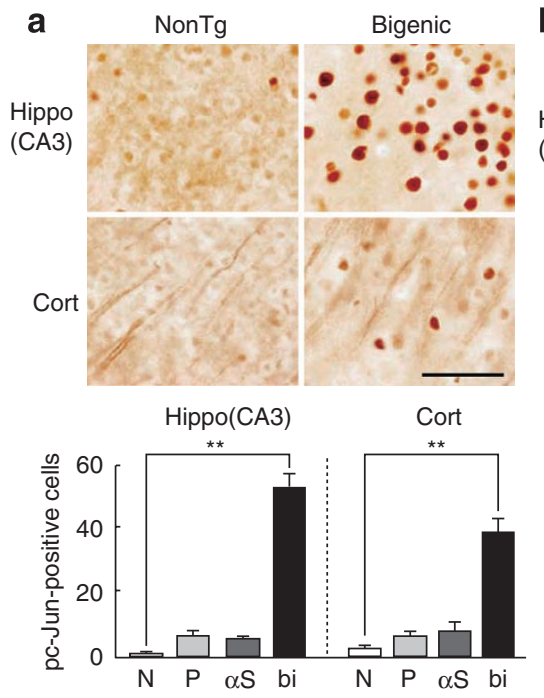

b
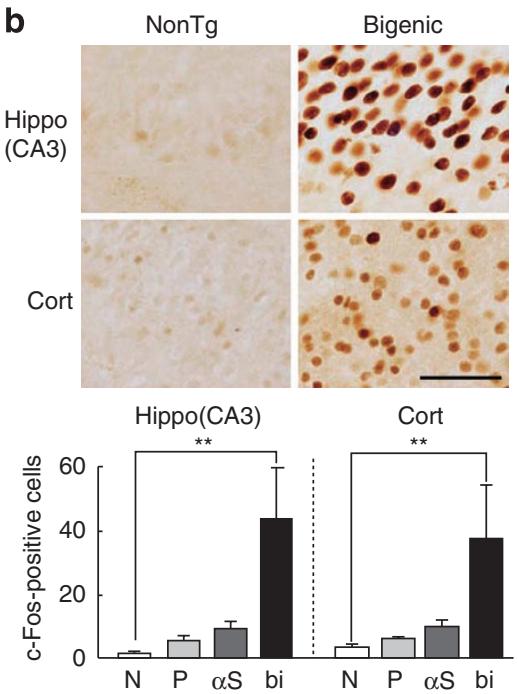

C
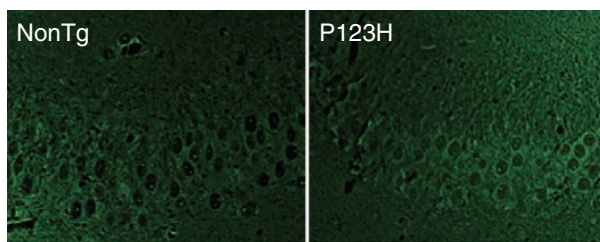

$\alpha S$
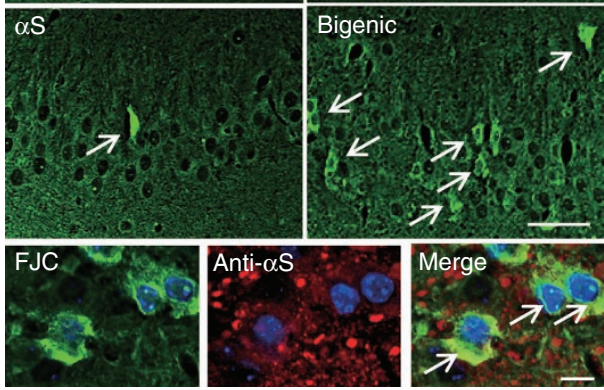

d
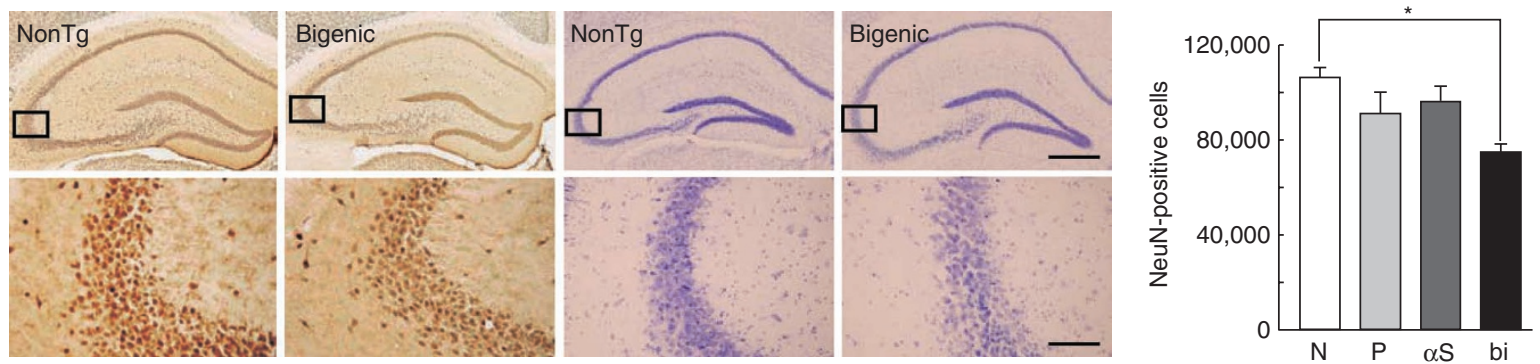

e
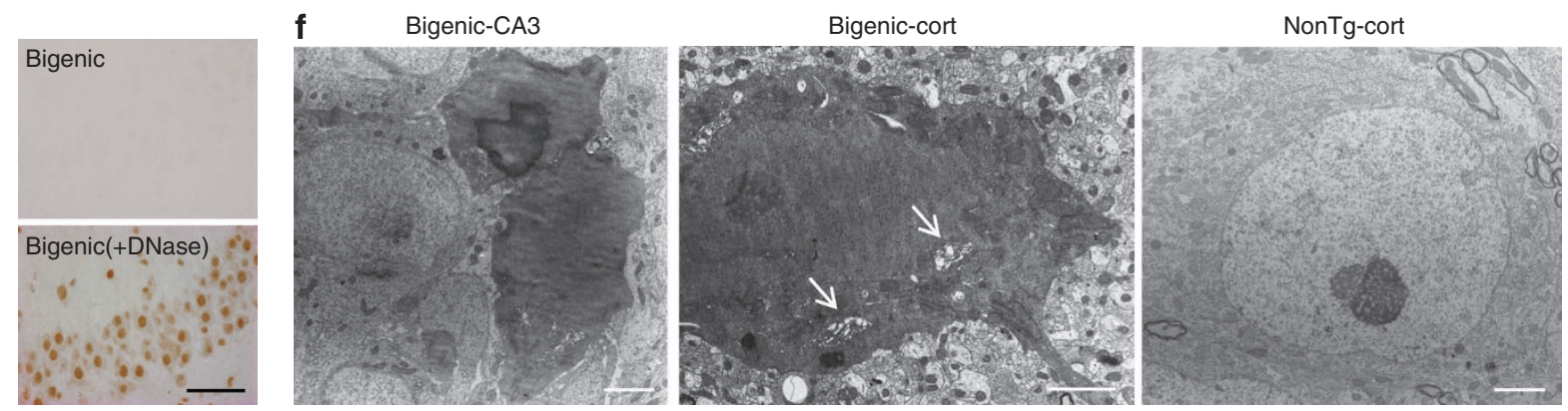

Figure 4 | Non-apoptotic neurodegeneration in bigenic mice overexpressing P123H $\boldsymbol{\beta S}$ and $\boldsymbol{\alpha}$ S. Hippocampus (hippo) CA3 and cortex (cort) of 9-monthold bigenic mice and littermates ( $\mathrm{P} 123 \mathrm{H} \beta \mathrm{S} \operatorname{tg}, \alpha \mathrm{S}$ tg and non-tg) were analysed. Abbreviations used in graph panels are non-tg, N; P123H $\beta S$ tg, $\mathrm{P} ; \alpha \mathrm{S} \operatorname{tg}, \alpha \mathrm{S}$; and bigenic, bi. (a, b) Immunohistochemistry of pc-Jun (a) and c-Fos (b). Representative images of bigenic mice and NonTg littermates are shown. Scale $\mathrm{bar}=50 \mu \mathrm{m}$. The graph shows quantification of the pc-Jun-positive cell count in $180 \times 180 \mu \mathrm{m}^{2}$ areas. Data are shown as mean \pm s.e.m. ( $n=5$ for $\mathbf{a}, n=8$ for $\mathbf{b}$ ). ${ }^{\star \star} P<0.01$ versus non-tg mice. (c) Evaluation of neurodegeneration by FJC staining. Representative images of the hippocampus from bigenic mice and from other littermates are shown (four figures in the upper panel). FJC-positive cells were observed in bigenic mice and to a lesser extent in $\alpha$ S tg mice (arrows). Scale bar $=50 \mu \mathrm{m}$. Lower images show that FJC-stained cells were also positive for $\alpha$ S (arrows) in bigenic mice. Nuclei were simultaneously stained with DAPI (4,6-diamidino-2-phenylindole). Scale bar $=10 \mu \mathrm{m}$. (d) Immunohistochemistry of NeuN. Representative images of NeuN (four panels to the left) and crystal violet staining (four panels to the right) of the hippocampus from bigenic mice and NonTg littermates are shown. Scale bar $=500 \mu \mathrm{m}$ (upper two panels) or $100 \mu \mathrm{m}$ (lower two panels). The figures given in the lower panels are magnifications of the figures given in the upper panel. The graph shows neuronal density based on the NeuN-immunoreactive cell count $\left(\right.$ cells $\left.\mathrm{mm}^{-3}\right)$ in the hippocampus. Data are shown as mean \pm s.e.m. $(n=5)$. ${ }^{\star} P<0.05$ versus non-tg mice.

(e) TUNEL staining. The hippocampus sections from bigenic mice were treated without (upper panel) or with DNase I (lower panel) ( $n=5)$. Representative figures are shown. Scale bar $=50 \mu \mathrm{m}$. (f) Appearance of dark degenerating neurons in the hippocampus and cortex of bigenic mice, but not in NonTg brains, in EM. Neuronal soma and dendritic processes both showed darkened features. Arrows indicate dilated Golgi apparatus in the shrunken cytoplasm (centre). In some cases, membrane structures of the nucleus and cytoplasm were obscure (left), which may reflect the terminal stage of neurodegeneration. Scale bar $=2 \mu \mathrm{m}$.

paraffin for preparation of $4 \mu \mathrm{m}$ serial sections for analysis. Free-floating brain sections were prepared by transcardiac perfusion with ice-cold saline, followed by $4 \%$ paraformaldehyde or Zamboni's solution containing glutaraldehyde. Serial sections of 40- $\mu \mathrm{m}$ thickness were then prepared. For the hippocampus and cortex, sagittal sections $\sim 1.5 \mathrm{~mm}$ lateral to the midline or coronal sections $\sim 1.5 \mathrm{~mm}$ posterior to the bregma, were used. For the striatum and globus pallidus, sagittal sections $\sim 1.5 \mathrm{~mm}$ lateral to the midline or coronal sections $\sim 0.5 \mathrm{~mm}$ anterior to the bregma were used. For the substantia nigra, coronal sections $\sim 2.6 \mathrm{~mm}$ posterior to the bregma were used. The location of the slice and identification of brain regions were determined by comparison to atlas images ${ }^{36}$.
Northern blot analysis. Total RNA isolated from whole brains was analysed by northern blotting, as previously described ${ }^{37}$. Hybridization was performed using ${ }^{32} \mathrm{P}-\mathrm{P} 123 \mathrm{H} \beta \mathrm{S}$ cDNA labelled by random priming. The filter was reprobed with ${ }^{32}$ P-labelled actin cDNA. The intensities of the hybridization bands were measured using BioMAX 1D image analysis software (Kodak).

Immunoblot analysis. Mice brains were homogenized in lysis buffer containing $1 \%$ Triton X-100 $0^{38}$ and centrifuged at $100,000 \mathrm{~g}$ for $30 \mathrm{~min}$. The supernatants $(10 \mu \mathrm{g})$ were resolved by SDS-PAGE and electroblotted onto nitrocellulose membranes. The membranes were blocked with $3 \%$ bovine serum albumin in Tris-buffered saline (TBS) plus 
a

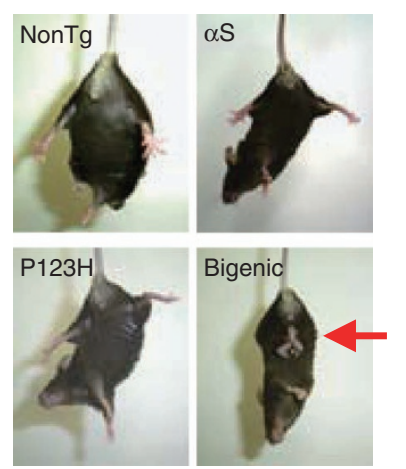

b

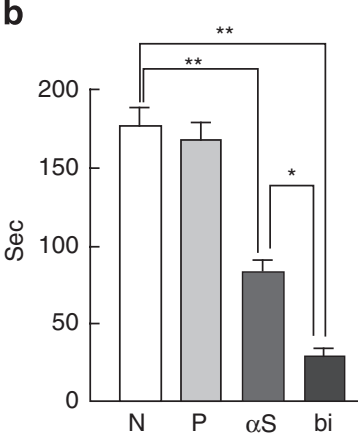

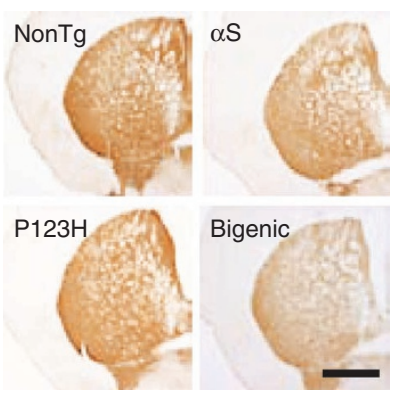

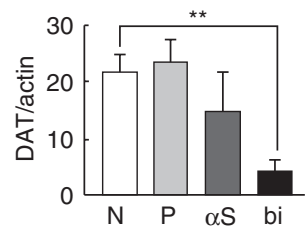

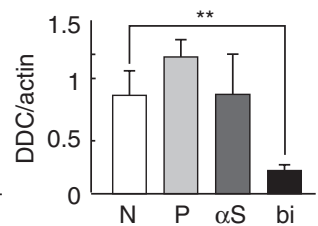
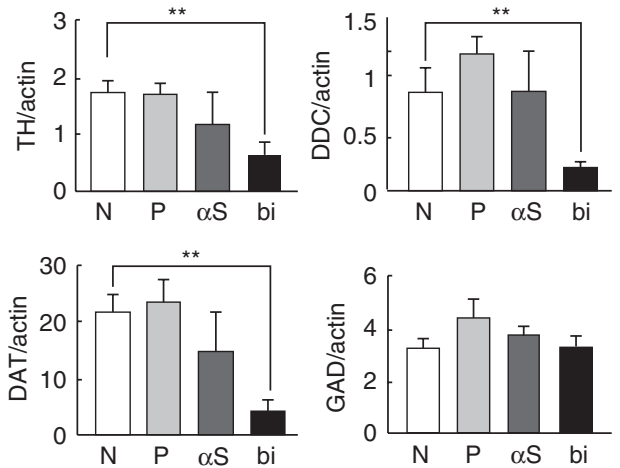

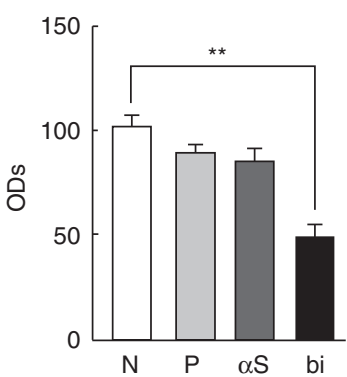

e

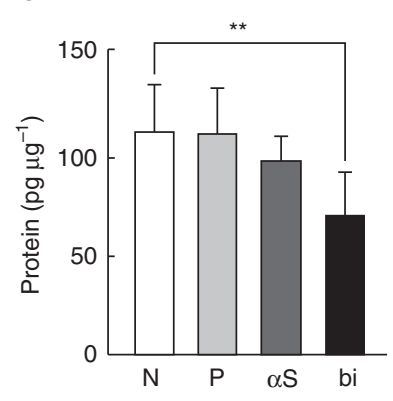

Figure 5 | Dopaminergic dysfunction in the striatum of bigenic mice. $(\mathbf{a}, \mathbf{b})$ Evaluation of the motor functions of bigenic (bi) mice and littermates ( $\alpha \mathrm{S}$ tg, $\alpha \mathrm{S} ; \mathrm{P} 123 \mathrm{H} \beta \mathrm{S} \mathrm{tg}, \mathrm{P}$; and non-tg, N) at 4 months. In a, a representative photograph of the tail-suspension assay shows strong front and hind limb clasping in bigenic mice (arrow), but not in other littermates. $\ln \mathbf{b}$, the rotarod treadmill test shows impaired motor performance in bigenic mice and to a lesser extent in $\alpha \mathrm{S}$ tg mice. Data are shown as mean \pm s.e.m. $(n=9-18) .{ }^{\star} P<0.05,{ }^{\star \star} P<0.01$. (c-e) Striata from 7-month-old bigenic mice and littermates (P123H $\beta S \mathrm{tg}, \alpha \mathrm{S}$ tg and non-tg) were analysed. Abbreviations used in graph panels are non-tg, N; P123H $\beta S \operatorname{tg}, \mathrm{P} ; \alpha \mathrm{S} \operatorname{tg}, \alpha \mathrm{S}$; and bigenic, bi. In c, representative images of TH immunohistochemistry are shown. Scale bar $=500 \mu \mathrm{m}$. The average optical densities (ODs) of the TH immunoreactivity was measured. Data are shown as mean \pm s.e.m. $(n=8) .{ }^{\star \star} P<0.01$ versus non-tg mice. In d, representative immunoblots of dopaminergic proteins (TH, L-dopa decarboxylase (DDC) and dopamine transporter (DAT)) and glutamic acid decarboxylase (GAD) and quantification of data against actin bands are shown. Data are shown as mean \pm s.e.m. $(n=8)$. ${ }^{\star \star} P<0.01$. In $\mathbf{e}$, dopamine concentrations in the striatum were measured by enzyme-linked immunosorbent assay. Data are shown as mean \pm s.e.m. $(n=5) .{ }^{\star} P<0.01$ versus non-tg mice.

$0.2 \%$ Tween 20 , followed by incubation with primary antibodies in TBS containing $3 \%$ bovine serum albumin. After washing, the membranes were further incubated with secondary antibody conjugated with horseradish peroxidase in TBS $(1: 5,000 \sim 10,000)$. Finally, the target proteins were visualized with the ECL plus system (GE Healthcare), followed by quantification using BioMAX 1D image analysis software.

Immunohistochemistry and immunofluorescence. Immunohistochemistry was performed as previously described ${ }^{7}$. Briefly, paraffin sections were autoclaved in $0.01 \mathrm{M}$ citrate buffer $(\mathrm{pH} 6.0)$ to retrieve antigen. Both paraffin and free-floating sections were then immersed in $0.3 \%$ hydrogen peroxide in methanol and incubated in $5 \%$ normal goat or rabbit serum for blocking. Sections were incubated with primary antibodies overnight at $4{ }^{\circ} \mathrm{C}$, followed by detection with biotinylated secondary antibodies and the Avidin-Biotin Complex Kit (Vector Laboratories). A positive reaction was detected using diaminobenzidine tetrahydrochloride containing $0.001 \%$ hydrogen peroxide. The results from at least seven images of serial sections for each mouse were used and an average value was calculated.

Cells were counted and optical densities were measured in some immunohistochemistry experiments. Stereological analysis was conducted with MCID image analysis software (InterFocus Imaging) for NeuN-immunoreactive cells in the hippocampal CA3 region and cerebral cortex and for TH-immunoreactive cells in the substantia nigra, as previously reported ${ }^{39,40}$. In brief, digital images of NeuN- and TH-immunoreactive neurons were acquired at $\times 50$ magnification on an Olympus microscope fitted with a video camera (Olympus). A counting frame created by the MCID image analysis software was systemically passed over the outlined CA3, cerebral cortex areas and substantia nigra pars compacta. The neurons were counted as they appeared within the counting frame. The average neuron density was obtained by totalling the number of neuron profiles and dividing by the calculated area ${ }^{11,42}$. As for P123H $\beta$ S-immunoreactive cells in the globus pallidus, positive cells with a diameter of $>3 \mu \mathrm{m}$ were selectively counted. For phospho-c-Jun- and c-Fos-immunoreactive cells, counting was conducted in areas of $180 \times 180 \mu \mathrm{m}^{2}$ in the hippocampus and cortex. For TH-immunoreactive fibres in the striatum, the average optical densities were evaluated as previously reported ${ }^{40}$.
Immunofluorescence was performed as previously described 7 . Both paraffin and free-floating sections were incubated with primary antibodies, followed by Alexa Fluor-conjugated secondary antibodies (Invitrogen). FJC staining was performed according to the manufacturer's instructions (Chemicon). Slides were observed by laser scanning confocal microscopy?

Electron microscopy. EM was performed as previously described with modifications ${ }^{15}$. The mice were deeply anaesthetized and killed by cardiac perfusion using ice-cold saline, followed by $2 \%$ paraformaldehyde and $2 \%$ glutaraldehyde. Brain tissues were post-fixed with $1 \%$ osmium tetroxide, followed by dehydration and embedding in Quetol 812 (Nisshin EM). Ultrathin sections were cut, stained with uranyl acetate and lead nitrate and observed using a Hitachi H-7650 electron microscope (Hitachi) equipped with a CanoScan 9900F digital imaging system (Canon).

Behaviour tests. Learning and memory were analysed with a Morris water maze test, as previously described, with modifications ${ }^{43}$. A circular pool (diameter $1.5 \mathrm{~m}$, height $30 \mathrm{~cm}$, temperature $23 \pm 1^{\circ} \mathrm{C}$ ) was filled with water containing non-fat dry milk. The escape platform (diameter $10 \mathrm{~cm}$ ) was located in the centre of one of the quadrants of the pool. To habituate mice to the water, the mice were pre-trained 1 day before starting the training session. Each mouse was placed on the visible platform, forced to jump into the water, allowed to swim for $60 \mathrm{~s}$ and then guided to the escape platform. This procedure was repeated twice for each mouse. During the training session, mice were trained to find the platform submerged $1 \mathrm{~cm}$ below the water surface. If the mouse failed to find the platform within $60 \mathrm{~s}$, it was guided to the platform and allowed to remain there for $15 \mathrm{~s}$. Mice received two trials per day and were trained for 10 days. On the last day of training, the probe test was performed to measure the searching behaviour in the target quadrant (quadrant where the platform was located during training) and platform area (the area where the platform was located) for $60 \mathrm{~s}$. A video tracking system (Topscan; Clever System) was used to analyse the escape latency and swim path.

To evaluate the spontaneous behaviour of mice, a home cage test was performed as previously described ${ }^{44}$ with modifications. One day before starting the test, mice were isolated and put into the test cage. A paper sheet was used as 
bedding material instead of sawdust for this test to prevent mice hiding in sawdust during recording. The recorded video during the dark phase (1900-0700 hours) was analysed using Home cage scan software (Clever System). The behavioural definitions, including 'Pause,' 'Sleep,' 'Twitch', 'Awaken,' 'Groom, 'Sniff', 'Rear up' and 'Hang Vertically', are described elsewhere ${ }^{44}$.

To measure locomotor activity, the rotarod test was performed as previously described ${ }^{7}$. Briefly, on the first day, mice were trained for three trials: the first one at 5 r.p.m., the second at 10 r.p.m. and the third at 20 r.p.m. On the second day, mice were tested for seven trials. Mice were placed individually on the rod and the speed of rotation was increased from 0 to 40 r.p.m. over 240 s. The length of time mice remained on the rod was recorded and the last four trials were averaged as a measure of motor function.

TUNEL assay. TUNEL staining was performed using the In Situ Cell Death Detec tion Kit POD (Roche) according to the manufacturer's instructions. For a positive control, the section was incubated with $10 \mathrm{U} \mathrm{ml}^{-1} \mathrm{DNase}$ I (Sigma) for $10 \mathrm{~min}$ at room temperature.

Dopamine enzyme-linked immunosorbent assay. Dopamine concentrations were measured using a Dopamine Research ELISA Kit according to the manufacturer's instructions (Labor Diagnostika).

Statistics. Data are presented as mean \pm s.e.m. Statistical differences were determined by either two-tailed $t$-test or analysis of variance, followed by a post-Fisher's protected least significant difference test, with $P<0.05$ considered to indicate a significant difference.

\section{References}

1. Nakajo, S., Tsukada, K., Omata, K., Nakamura, Y. \& Nakaya, K. A new brainspecific $14-\mathrm{kDa}$ protein is a phosphoprotein. Its complete amino acid sequence and evidence for phosphorylation. Eur. J. Biochem. 217, 1057-1063 (1993).

2. Jakes, R., Spillantini, M. G. \& Goedert, M. Identification of two distinct synucleins from human brain. FEBS Lett. 345, 27-32 (1994).

3. Ueda, K. et al. Molecular cloning of cDNA encoding an unrecognized component of amyloid in Alzheimer disease. Proc. Natl Acad. Sci. USA 90, 11282-11286 (1993).

4. Clayton, D. F. \& George, J. M. The synucleins: a family of proteins involved in synaptic function, plasticity, neurodegeneration and disease. Trends Neurosci. 21, 249-254 (1998).

5. Biere, A. L. et al. Parkinson's disease-associated alpha-synuclein is more fibrillogenic than beta- and gamma-synuclein and cannot cross-seed its homologs. J. Biol. Chem. 275, 34574-34579 (2000).

6. Giasson, B. I., Murray, I. V., Trojanowski, J. Q. \& Lee, V. M. A hydrophobic stretch of 12 amino acid residues in the middle of alpha-synuclein is essential for filament assembly. J. Biol. Chem. 276, 2380-2386 (2001).

7. Hashimoto, M., Rockenstein, E., Mante, M., Mallory, M. \& Masliah, E. Beta-Synuclein inhibits alpha-synuclein aggregation: a possible role as an anti-parkinsonian factor. Neuron 32, 213-223 (2001).

8. Fan, Y. et al. Beta-synuclein modulates alpha-synuclein neurotoxicity by reducing alpha-synuclein protein expression. Hum. Mol. Genet. 15, 3002-3011 (2006).

9. Hashimoto, M. et al. An antiaggregation gene therapy strategy for Lewy body disease utilizing beta-synuclein lentivirus in a transgenic model. Gene Ther. 11, 1713-1723 (2004).

10. Uversky, V. N. et al. Biophysical properties of the synucleins and their propensities to fibrillate: inhibition of alpha-synuclein assembly by beta- and gamma-synucleins. J. Biol. Chem. 277, 11970-11978 (2002).

11. Park, J. Y. \& Lansbury, P. T. Jr. Beta-synuclein inhibits formation of alphasynuclein protofibrils: a possible therapeutic strategy against Parkinson's disease. Biochemistry 42, 3696-3700 (2003).

12. Sharon, R. et al. The formation of highly soluble oligomers of alpha-synuclein is regulated by fatty acids and enhanced in Parkinson's disease. Neuron 37, 583-595 (2003).

13. Israeli, E. \& Sharon, R. Beta-synuclein occurs in vivo in lipid-associated oligomers and forms hetero-oligomers with alpha-synuclein. J. Neurochem. 108, 465-474 (2009).

14. Ohtake, H. et al. Beta-synuclein gene alterations in dementia with Lewy bodies. Neurology 63, 805-811 (2004).

15. Wei, J. et al. Enhanced lysosomal pathology caused by beta-synuclein mutants linked to dementia with Lewy bodies. J. Biol. Chem. 282, 28904-28914 (2007).

16. Wei, J. et al. Protective role of endogenous gangliosides for lysosomal pathology in a cellular model of synucleinopathies. Am. J. Pathol. 174, 1891-1909 (2009).

17. Zaccai, J., McCracken, C. \& Brayne, C. A systematic review of prevalence and incidence studies of dementia with Lewy bodies. Age Ageing 34, 561-566 (2005).

18. Carpenter, S. Proximal axonal enlargement in motor neuron disease. Neurology 18, 841-851 (1968).
19. Seitelberger, F. Neuropathological conditions related to neuroaxonal dystrophy. Acta Neuropathol. 5(Suppl 5), 17-29 (1971).

20. Cuervo, A. M., Stefanis, L., Fredenburg, R., Lansbury, P. T. \& Sulzer, D. Impaired degradation of mutant alpha-synuclein by chaperone-mediated autophagy. Science 305, 1292-1295 (2004).

21. Wichmann, T. \& DeLong, M. R. Functional and pathophysiological models of the basal ganglia. Curr. Opin. Neurobiol. 6, 751-758 (1996).

22. Rockenstein, E. et al. Differential neuropathological alterations in transgenic mice expressing alpha-synuclein from the platelet-derived growth factor and Thy-1 promoters. J. Neurosci. Res. 68, 568-578 (2002).

23. Kramer, B. C. \& Mytilineou, C. Alterations in the cellular distribution of bcl-2, bcl-x and bax in the adult rat substantia nigra following striatal 6-hydroxydopamine lesions. J. Neurocytol. 33, 213-223 (2004).

24. Liu, L., Hsu, S. S., Kalia, S. K. \& Lozano, A. M. Injury and strain-dependent dopaminergic neuronal degeneration in the substantia nigra of mice after axotomy or MPTP. Brain Res. 994, 243-252 (2003).

25. Gallyas, F., Kiglics, V., Baracskay, P., Juhasz, G. \& Czurko, A. The mode of death of epilepsy-induced 'dark' neurons is neither necrosis nor apoptosis: an electron-microscopic study. Brain Res. 1239, 207-215 (2008).

26. Turmaine, M. et al. Nonapoptotic neurodegeneration in a transgenic mouse model of Huntington's disease. Proc. Natl Acad. Sci. USA 97, 8093-8097 (2000).

27. Nuber, S. et al. Neurodegeneration and motor dysfunction in a conditional model of Parkinson's disease. J. Neurosci. 28, 2471-2484 (2008).

28. Lewandowska, E., Kurkowska-Jastrzebska, I., Lechowicz, W., Czlonkowska A. \& Czlonkowski, A. Ultrastructural changes in substantia nigra and striatum observed on a mouse model of Parkinson's disease induced by MPTP administration. Folia Neuropathol. 37, 239-242 (1999).

29. Cuellar, T. L. et al. Dicer loss in striatal neurons produces behavioral and neuroanatomical phenotypes in the absence of neurodegeneration. Proc. Natl Acad. Sci. USA 105, 5614-5619 (2008).

30. Lalonde, R. Motor abnormalities in weaver mutant mice. Exp. Brain Res. 65, 479-481 (1987)

31. Bertoncini, C. W. et al. Structural characterization of the intrinsically unfolded protein beta-synuclein, a natural negative regulator of alpha-synuclein aggregation. J. Mol. Biol. 372, 708-722 (2007).

32. Cole, R. N. \& Hart, G. W. Cytosolic O-glycosylation is abundant in nerve terminals. J. Neurochem. 79, 1080-1089 (2001).

33. Galvin, J. E., Giasson, B., Hurtig, H. I., Lee, V. M. \& Trojanowski, J. Q. Neurodegeneration with brain iron accumulation, type 1 is characterized by alpha-, beta-, and gamma-synuclein neuropathology. Am. J. Pathol. 157, 361-368 (2000)

34. Galvin, J. E., Uryu, K., Lee, V. M. \& Trojanowski, J. Q. Axon pathology in Parkinson's disease and Lewy body dementia hippocampus contains alpha-, beta-, and gamma-synuclein. Proc. Natl Acad. Sci. USA 96, 13450-13455 (1999).

35. Ninkina, N. et al. \{Gamma\}-synucleinopathy-neurodegeneration associated with overexpression of the mouse protein. Hum. Mol. Genet. 18, 1779-1794 (2009).

36. Franklin, K. \& Paxinos, G. The Mouse Brain In Stereotaxic Cordinate, 3rd edn (Academic Press, 2008)

37. Fujita, M. et al. Differential expression of secreted frizzled-related protein 4 in decidual cells during pregnancy. J. Mol. Endocrinol. 28, 213-223 (2002).

38. Fujita, M. et al. alpha-Synuclein stimulates differentiation of osteosarcoma cells: relevance to down-regulation of proteasome activity. J. Biol. Chem. 282, 5736-5748 (2007).

39. Volpe, B. T., Wildmann, J. \& Altar, C. A. Brain-derived neurotrophic factor prevents the loss of nigral neurons induced by excitotoxic striatal-pallidal lesions. Neuroscience 83, 741-748 (1998).

40. Sugama, S. et al. Temporal and sequential analysis of microglia in the substantia nigra following medial forebrain bundle axotomy in rat. Neuroscience 116, 925-933 (2003)

41. Coggeshall, R. E. A consideration of neural counting methods. Trends Neurosci. 15, 9-13 (1992)

42. Gundersen, H. J. Stereology: the fast lane between neuroanatomy and brain function - or still only a tightrope? Acta Neurol. Scand. 137, 8-13 (1992).

43. Masliah, E. et al. beta-amyloid peptides enhance alpha-synuclein accumulation and neuronal deficits in a transgenic mouse model linking Alzheimer's disease and Parkinson's disease. Proc. Natl Acad. Sci. USA 98, 12245-12250 (2001).

44. Steele, A.D., Jackson, W.S., King, O.D. \& Lindquist, S. The power of automated high-resolution behavior analysis revealed by its application to mouse models of Huntington's and prion diseases. Proc. Natl Acad. Sci. USA 104, 1983-1988 (2007).

45. Kruger, R. et al. Ala30Pro mutation in the gene encoding alpha-synuclein in Parkinson's disease. Nat. Genet. 18, 106-108 (1998).

46. Polymeropoulos, M. H. et al. Mutation in the alpha-synuclein gene identified in families with Parkinson's disease. Science 276, 2045-2047 (1997).

47. Zarranz, J. J. et al. The new mutation, E46K, of alpha-synuclein causes Parkinson and Lewy body dementia. Ann. Neurol. 55, 164-173 (2004). 


\section{Acknowledgments}

We are grateful to Ms Kyoko Ajiki (Tokyo Metropolitan Institute for Neuroscience) for technical help with EM. This work was supported in part by a grant-in-aid for Science Research (Young Scientist B, 21700399 to M.F.; Cell Innovation Project to S.I.; Basic

Science Research B, 21300135 to M.H.; Challenging Exploratory Research, 20650053 to M.H.) from the Ministry of Education, Culture, Sports, Science, and Technology, Japan; by the Nakatomi Foundation (to M.F.); NIBIO grant (to S.I.); Takeda Foundation (to M.H.); Novartis Foundation for Gerontological Research (to M.H.); and NIH Grants AG18440, AG022074, AG10435 and ES016731 (to E.M.)

\section{Author contributions}

T.Tsu and S.I. performed microinjections. M.F., S.S., K.S., A.S., M.N. and E.R. analysed transgenic mice. M.F., T.Tak, M.W., Y.T., J.W., A.R.L., E.M., S.I. and M.H. designed and analysed the data. M.F., E.M., S.I. and M.H. supervised and wrote the paper. All authors interpreted the data.

\section{Additional information}

Supplementary Information accompanies this paper on http://www.nature.com/ naturecommunications

Competing financial interests: The authors declare no competing financial interests.

Reprints and permission information is available online at http://npg.nature.com/ reprintsandpermissions/

How to cite this article: Fujita, M. et al. A $\beta$-synuclein mutation linked to dementia produces neurodegeneration when expressed in mouse brain. Nat. Commun. 1:110 doi: 10.1038/ncomms1101 (2010).

License: This work is licensed under a Creative Commons Attribution-NonCommercialShare Alike 3.0 Unported License. To view a copy of this license, visit http:// creativecommons.org/licenses/by-nc-sa/3.0/ 